\title{
Bioelectrical impedance analysis for predicting postoperative complications and survival after liver resection for hepatocellular carcinoma
}

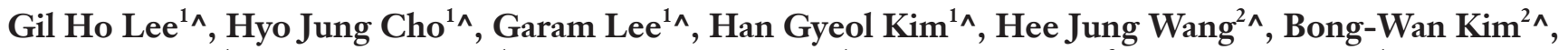 \\ Mi Young Lee ${ }^{\wedge} \wedge$, So Young Yoon ${ }^{1 \wedge}$, Choong-Kyun Noh $^{1 \wedge}$, Chul Won Seo ${ }^{3 \wedge}$, Jung Woo Eun ${ }^{1 \wedge}$, \\ Jae Youn Cheong ${ }^{1 \wedge}$, Sung Won $\mathrm{Cho}^{1 \wedge}$, Soon Sun Kim ${ }^{1 \wedge}$ \\ ${ }^{1}$ Department of Gastroenterology, Ajou University School of Medicine, Suwon, Republic of Korea; ${ }^{2}$ Department of Surgery, Ajou University School \\ of Medicine, Suwon, Republic of Korea; ${ }^{3}$ Department of Biomedical Sciences, Ajou University School of Medicine, Suwon, Republic of Korea \\ Contributions: (I) Conception and design: HJ Wang, BW Kim, HJ Cho, SS Kim; (II) Administrative support: JY Cheong, SW Cho; (III) Provision of \\ study materials or patients: HJ Wang, BW Kim; (IV) Collection and assembly of data: GH Lee, G Lee, HG Kim, MY Lee, SY Yoon, CW Seo, JW \\ Eun; (V) Data analysis and interpretation: GH Lee, CK Noh; (VI) Manuscript writing: All authors; (VII) Final approval of manuscript: All authors. \\ Correspondence to: Soon Sun Kim, MD, PhD. Department of Gastroenterology, Ajou University School of Medicine, 164, Worldcup-ro, Yeongtong- \\ gu, Suwon, Gyeonggi-do, 16499, Republic of Korea. Email: cocorico99@gmail.com.
}

Background: Bioelectrical impedance analysis provides information on body composition and nutritional status. However, it's unclear whether the preoperative edema index or phase angle predicts postoperative complication or mortality in patients with hepatocellular carcinoma (HCC). Thus, we investigated whether preoperative bioelectrical impedance analysis could predict postoperative complications and survival in patients with HCC.

Methods: Seventy-nine patients who underwent hepatectomy for hepatocellular carcinoma were prospectively enrolled and bioelectrical impedance analysis was performed before surgery. Postoperative ascites or acute kidney injury and patients' survival were monitored after surgery.

Results: Among 79 patients, 35 (44.3\%) developed ascites or acute kidney injury after hepatectomy. In multivariate analysis, a high preoperative edema index (extracellular water/total body water) (>0.384) (odds ratio 3.96; $95 \%$ confidence interval: 1.03-15.17; $\mathrm{P}=0.045$ ) and higher fluid infusion during surgery (odds ratio 1.36 ; $95 \%$ confidence interval: $1.04-1.79 ; \mathrm{P}=0.026$ ) were identified as significant risk factors for ascites or acute kidney injury after hepatectomy. Subgroup analyses showed that the edema index was a significant predictor of ascites or acute kidney injury in patients with cirrhosis. Tumor size was the only significant predictive factor for short-term survival after hepatectomy.

Conclusions: The preoperative edema index using bioelectrical impedance analysis can be used as a predictor of post-hepatectomy complication, especially in patients with liver cirrhosis.

Keywords: Hepatocellular carcinoma (HCC); hepatectomy; electrical impedance; postoperative complications

Submitted Jul 07, 2020. Accepted for publication Nov 16, 2020.

doi: $10.21037 /$ atm-20-5194

View this article at: http://dx.doi.org/10.21037/atm-20-5194

\footnotetext{
^ ORCID: Gil Ho Lee, 0000-0001-7695-0828; Hyo Jung Cho, 0000-0003-4792-8335; Garam Lee, 0000-0002-7068-5610; Han Gyeol Kim, 0000-0003-2582-0059; Hee Jung Wang, 0000-0002-5300-166x; Bong-Wan Kim, 0000-0001-9059-0451; Mi Young Lee, 0000-00020171-967x; So Young Yoon, 0000-0003-0637-6415; Choong-Kyun Noh, 0000-0002-3607-8120; Chul Won Seo, 0000-0001-6759-3267; Jung Woo Eun, 0000-0002-2461-6702; Jae Youn Cheong, 0000-0001-6246-1783; Sung Won Cho, 0000-0002-0232-0492; Soon Sun Kim, 0000-0002-6862-1896.
} 


\section{Introduction}

Liver cancer, including hepatocellular carcinoma (HCC), is the sixth most common cancer and the fourth leading cause of cancer death worldwide, with about 841,000 new cases and 782,000 deaths annually (1). It is mainly caused by damage to the liver parenchyma in patients with hepatitis due to viral infection or alcoholic liver disease. Hepatectomy is an effective HCC treatment option in patients who are not eligible for liver transplantation, and although recent advances in medicine have resulted in notable improvements in postoperative mortality $(2,3)$, postoperative morbidity is still unsatisfactory (4). Ascites is one of the most common postoperative complications after liver resection, with an incidence of $12.1-41.7 \%$, and may lead to postoperative dehydration, electrolyte imbalance, infection, dyspnea, and hepatic failure (5). In patients undergoing hepatectomy, postoperative ascites is associated with overall postoperative morbidity and acute renal failure, and requires special treatment (including albumin infusion, diuretics, and paracentesis) and prolonged hospital stay (6). Furthermore, postoperative ascites is associated with a high incidence of HCC recurrence and mortality (7). It occurs due to the imbalance between the portal venous inflow and the diminished hepatic venous outflow of the remnant liver and is associated with acute portal hypertension (8). Because the majority of patients undergoing hepatectomy for HCC suffer from underlying liver disease, this risk is increased. The risk factors for postoperative ascites include liver cirrhosis, low serum albumin, low platelet count, high indocyanine green level, notable blood loss, large tumor size, and red blood cell transfusion $(6,7,9)$. Acute kidney injury (AKI) after hepatectomy is a wellknown complication, with up to $15.1 \%$ incidence (10). AKI following hepatectomy is associated with shortterm mortality $(11,12)$. Known risk factors for AKI after hepatectomy include a high Model for End-stage Liver Disease score, the presence of non-dialytic chronic kidney disease, biliary obstruction in the preoperative period, perioperative hemodynamics instability, bleeding, and sepsis (13).

Bioelectrical impedance analysis (BIA) is a simple, noninvasive, reproducible technique for evaluating body water and composition (14). This technique measures the resistance, which is related to the composition of the tissues such as intracellular and extracellular water (15). This technique also measures the reactance and phase angle at $50 \mathrm{kHz}$. The results of BIA correlate with prognosis in various populations, including patients with cancer (16-18). Also, sarcopenia and phase angle detected by BIA is a negative prognostic factor in two studies $(19,20)$. Recent studies have reported that various factors that can be measured by BIA in patients with various carcinomas are related to the prognosis. Yasui-Yamada et al. reported that the phase angle measured by BIA may play an important role in short term and long term postoperative prognosis in patients with gastrointestinal or hepatobiliary cancer (21). Barao et al. reported that the phase angle and patient-generated subjective global assessment were prognostic factors in patients with colorectal cancer (22). Additionally, Axelsson et al. reported that the phase angle at diagnosis and the standardized phase angle were significant factors for survival in patients with advanced head and neck cancer. Studies have also reported that various factors measured by BIA in patients with cirrhosis of the liver are associated with prognosis and morbidity (23). Recently, one study reported that sarcopenia and phase angle is a prognostic indicator for survival in cirrhotic patients with HCC (24). Another study reported that the edema index (extracellular water/total body water) increases with hepatic dysfunction in liver cirrhosis, and the incidence of ascites is higher when the edema index is greater than 0.398 in patients with cirrhosis (25). The presence of sarcopenia is associated with the occurrence of cirrhotic complications and poor prognosis (19); therefore, confirming that the presence of sarcopenia may be clinically important information that can be obtained via BIA. However, to our knowledge, no study has examined whether the preoperative edema index or phase angle predicts postoperative complication or mortality in patients with HCC. Therefore, this study aimed to assess whether factors such as phase angle, presence of sarcopenia, and edema index, which can be measured through BIA, affect postoperative complications, including ascites and AKI, and prognosis after liver resection in patients with HCC. We present the following article in accordance with the transparent reporting of a multivariable prediction model for individual prognosis or diagnosis (TRIPOD) reporting checklist (available at http://dx.doi.org/10.21037/atm-205194).

\section{Methods}

\section{Patients}

We prospectively enrolled the patients who underwent 
hepatectomy for HCC at our hospital from July 2016 to June 2018. Inclusion criteria were patients over 19 years old scheduled to undergo liver resection for hepatocellular carcinoma. Exclusion criteria were: (I) patients who had previously received implantable electronic devices; (II) patients who had previously undergone liver transplantation; (III) patients who refused BIA. Diagnosis of underlying liver disease was confirmed by the histologic examination after hepatectomy. The study was conducted in accordance with the Declaration of Helsinki (as revised in 2013). This study was approved by the Institutional Review Board of Ajou University Hospital (AJIRBMED-OBS-16-287), and all patients provided informed consent.

\section{BIA and definition of edema index}

BIA was performed on the day of admission before intravenous hydration using a multi-frequency BIA InBody 770 scanner (InBody, Seoul, Republic of Korea). BIA was performed with patients in a standing position according to the manufacturer's instructions after shoes, coats, and sweaters had been removed. The BIA scanner used frequencies $1,5,50,260,500$, and $1,000 \mathrm{kHz}$ over 60 seconds. By BIA, phase angle, extracellular fluid and total body fluid, body cell mass, and appendicular skeletal muscle mass can be derived by computed analysis. Edema index can be calculated as the ratio of extracellular fluid to total body fluid. Sarcopenia was defined using height-adjusted appendicular skeletal muscle mass (appendicular skeletal muscle mass $/$ height ${ }^{2}, \mathrm{~kg} / \mathrm{m}^{2}$ ), and was $<7.0 \mathrm{~kg} / \mathrm{m}^{2}$ for men and $<5.7 \mathrm{~kg} / \mathrm{m}^{2}$ for women according to a previous study involving Asians (26).

\section{Surgical procedure}

Patients with HCC were classified according to modified Union for International Cancer Control, and liver function was assessed by Child-Pugh score and indocyanine green 15 ' retention test (ICGR15). The surgery's extent was determined according to the judgment of the liver surgery team considering tumor location, stage, liver function, and performance status.

\section{Definition of clinical outcome}

We defined "postoperative ascites" as peak drainage of ascites $>500 \mathrm{~mL}$ /day during hospitalization, or when patients needed diuretics to control ascites, according to previous study (5). AKI was defined according to the Kidney Disease Improving Global Outcomes guideline as follows: stage 1, a peak serum creatinine of $1.5-1.9$ times baseline or $\geq 0.3 \mathrm{mg} / \mathrm{dL}(\geq 26.5 \mu \mathrm{mol} / \mathrm{L})$ elevation; stage 2 , a peak serum creatinine of 2.0-2.9 times baseline; and stage 3, a peak serum creatinine of $>3.0$ times baseline or increase in serum creatinine to $\geq 4.0 \mathrm{mg} / \mathrm{dL}(\geq 353.6 \mu \mathrm{mol} / \mathrm{L})$ or initiation of renal replacement therapy (27). Liver cirrhosis and degree of hepatic fibrosis were defined by pathological reports after liver resection. Patients were followed until June 2018 for survival analysis.

\section{Statistical analyses}

The sample size was calculated via a review of previous studies. The incidence of ascites after hepatectomy was determined to be $10.3 \%$ based on previous study (5). In this study, Child-Pugh class C or severe preoperative complications in an HCC patient are considered contraindications for hepatic resection. Also, Major hepatic resection was considered for patients who had an ICGR 15 of less than $20 \%$. Because the subjects in this study and our study were similar, we estimated the incidence of postoperative ascites or AKI as $10.3 \%$ even though various incidences were reported in several studies. The incidence of ascites after hepatectomy has been reported to be $10.3 \%$ and the incidence of ascites is reported to be 4.04 times according to the edema index (25). When the incidence of ascites or AKI after hepatectomy according to edema index was analyzed using a multivariable logistic regression model, the required number of study subjects was calculated as 76 , at a power of $80 \%$ and alpha of 0.05 (28). All data are presented as mean \pm standard deviation or as numbers and percentages. Categorical variables were analyzed using the chi-square or Fisher's exact test. Quantitative data were analyzed using the independent $t$-test. Factors associated with the development of postoperative ascites or AKI were analyzed via binary logistic regression analysis. The area under the curve (AUC) was calculated for measuring overall ascites or AKI prediction accuracy of edema index. Cox proportional hazards analysis was used to identify factors associated with survival. Statistical analyses were performed using SPSS for Windows version 21.0 (SPSS Inc., Chicago, Illinois, United States). A P value of $<0.05$ was considered statistically significant. 
Table 1 Baseline characteristics of the study population

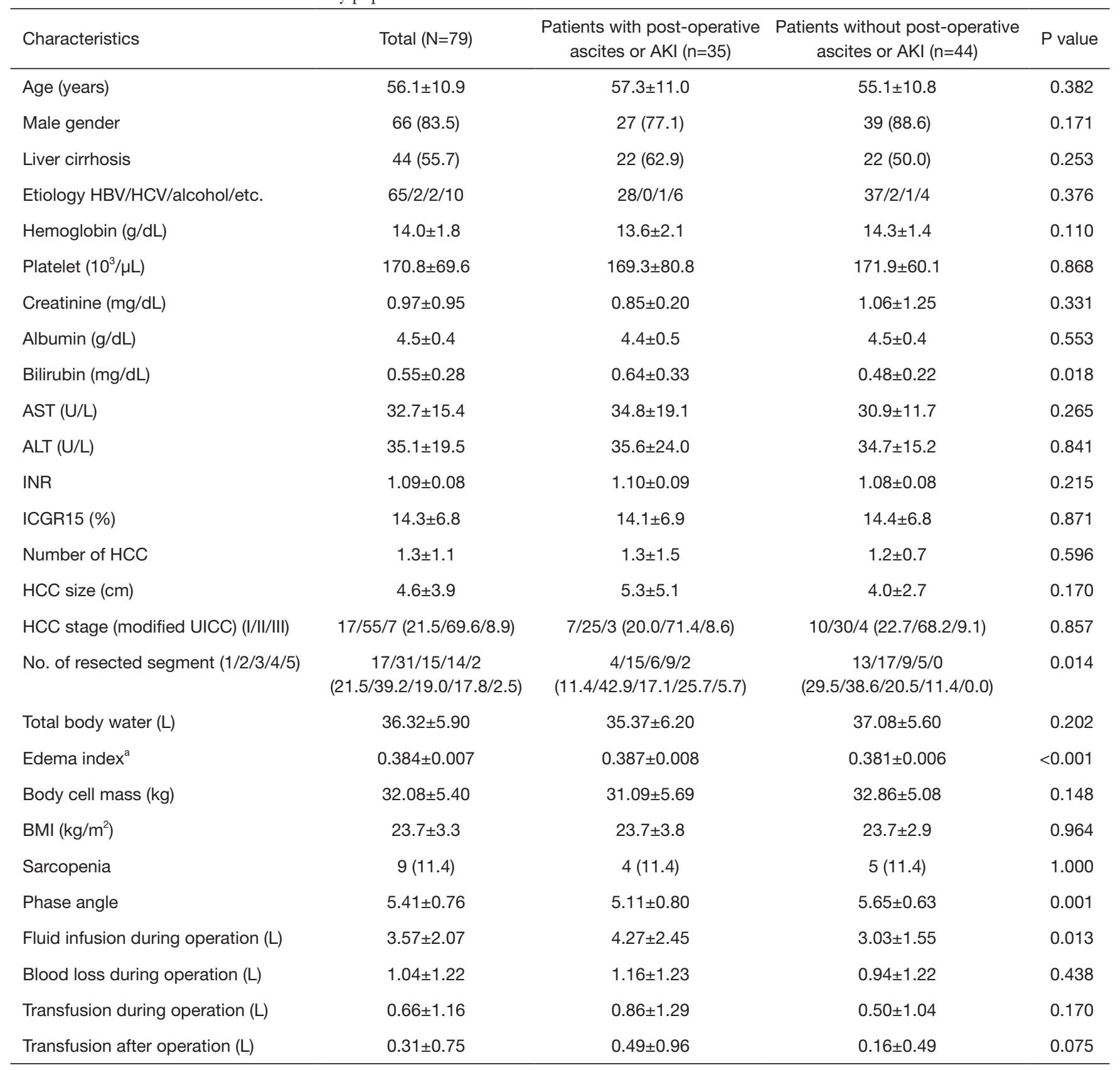

Continuous variables are expressed as mean \pm standard deviations and categorical variables are expressed as numbers (\%). ${ }^{\text {, }}$, edema index was calculated using extracellular water/total body water. AKI, acute kidney injury; HBV, hepatitis B virus; HCV, hepatitis C virus; AST, aspartate aminotransferase; ALT, alanine aminotransferase; INR, international normalized ratio; ICGR15, indocyanine green 15' retention test; HCC, hepatocellular carcinoma; UICC, Union for International Cancer Control; BMI, body mass index.

\section{Results}

\section{Baseline characteristics and surgical procedure}

Seventy-nine patients were included in the study and their baseline characteristics are summarized in (Table 1). The mean patient age was $56.1 \pm 10.9$ years, and $83.5 \%$ were men. Forty-four $(55.7 \%)$ had liver cirrhosis. The mean HCC size was $4.6 \pm 3.9 \mathrm{~cm}$, and $88.6 \%$ had only one 
HCC. The mean preoperative ICGR15 was $14.3 \% \pm 6.8 \%$. Patients underwent various surgeries ranging from segmentectomy to lobectomy depending on tumor size and location. The number of resected segments were ranging from 1 to 5 . The most frequent surgery was right lobectomy (14\%). The median hospitalization duration was 16 (range, 10-45) days.

\section{Incidence of postoperative ascites and AKI}

Among the 79 patients, $35(44.3 \%)$ and $4(5.1 \%)$ developed postoperative ascites and AKI, respectively; 8 , 19 , and 8 patients had ascites $<500$, between $500-1,000$, and $>1,000 \mathrm{~mL} /$ day, respectively. Four cases of AKI were classified as grade I and II in 2 cases each. Three patients recovered during hospitalization. One patient with grade I AKI did not recover renal function during hospitalization, but fully recovered 1 month later. Four patients died during the median follow-up of 10.9 months; all of these experienced HCC recurrences and died because of disease progression.

\section{Risk factors for postoperative ascites or AKI in all patients}

In univariate analyses, a higher edema index, low phase angle, higher intraoperative fluid infusion, and more extensive surgery (higher number of resected segments) were significant risk factors for ascites or AKI in patients who underwent liver resection. However, liver cirrhosis and sarcopenia were not significant risk factors for postoperative ascites or AKI. Specifically, there was a significant difference in the mean values of the edema index (0.387 vs. $0.381, \mathrm{P}<0.001)$ between the groups with and without ascites or AKI. Based on the median value of the edema index, the incidence of postoperative ascites or AKI was higher in patients with a high edema index $(>0.384)$ than in those with a low edema index $(\leq 0.384)(64.9 \%$ vs. $31.4 \%, \mathrm{P}=0.001)$. In multivariate analysis, edema index $>0.384$ [odds ratio (OR) 3.96; $95 \%$ confidence interval (CI): 1.03-15.17; $\mathrm{P}=0.045]$ and higher fluid infusion during surgery (OR 1.36; 95\% CI: 1.04-1.79; $\mathrm{P}=0.026)$ were significant risk factors for postoperative ascites or AKI (Table 2). The AUC of edema index was 0.712 (95\% CI: $0.595-0.829 ; \mathrm{P}=0.001$ ) for predicting postoperative ascites or AKI (Figure 1). The edema index proved to be sensitive $(68.6 \%)$ and specific $(70.5 \%)$ when using cutoffs as edema index $>0.384$.

\section{Risk factors for postoperative ascites or AKI in two subgroups (patients with and without liver cirrbosis)}

We conducted a subgroup analysis to determine whether the edema index is useful in the presence of liver cirrhosis. Among the 44 cirrhotic patients, 22 developed postoperative ascites or AKI. In univariate analyses, a higher edema index and higher fluid infusion during surgery were significant risk factors for ascites or AKI in patients who underwent liver resection. Specifically, there was no significant difference between those with and without ascites or AKI with regard to the mean edema index values (0.385 vs. 0.381, $\mathrm{P}=0.056$ ). However, the incidence of ascites or AKI was higher in patients with a high edema index (68.4\% vs. $36.0 \%, \mathrm{P}=0.033$ ). In multivariate analysis, edema index $>0.384$ and higher fluid infusion during surgery were significant risk factors for postoperative ascites or AKI (Table 3). The AUC of the edema index was 0.645 (95\% CI: $0.478-0.811 ; \mathrm{P}=0.100)$ for predicting postoperative ascites or AKI.

Similarly, a subgroup analysis was performed on patients without cirrhosis $(n=35,44.3 \%)$. Among these, 13 developed postoperative ascites or AKI. In univariate analyses, a higher edema index, low phase angle, more extensive surgery, and larger HCC were significant risk factors for ascites or AKI in patients who underwent liver resection (Table 4). There was a significant difference in the mean edema index between those with and without ascites or AKI (0.390 vs. 0.382, $\mathrm{P}=0.001)$. There was a significant difference in the incidence of ascites or AKI (61.1\% vs. $11.8 \%, \mathrm{P}=0.003$ ) between those with a high and low edema index. However, multivariate analysis showed that the edema index was not a significant predictor of postoperative ascites or AKI in patients without cirrhosis (OR 4.38; 95\% CI: $0.35-55.38 ; \mathrm{P}=0.254)$. The AUC of the edema index was 0.830 (95\% CI: 0.696-0.965; $\mathrm{P}=0.001$ ) for predicting postoperative ascites of AKI.

\section{Predictive factors for postoperative survival in HCC patients}

Four patients died during follow-up. Multivariate analysis showed that a large tumor size was the only predictive factor for poor survival after hepatectomy (hazard ratio 1.72, 95\% CI: 1.05-2.83; P=0.033). Phase angle, sarcopenia, and edema index were not predictive of survival (Table 5 , Figure 2). 
Table 2 Risk factors for predicting postoperative ascites or AKI in all patients

\begin{tabular}{|c|c|c|c|c|}
\hline Factors & \multicolumn{2}{|c|}{ Univariate analysis } & \multicolumn{2}{|c|}{ Multivariate analysis } \\
\hline Age, $\geq 55$ years & $1.01(0.41-2.48)$ & 0.977 & & \\
\hline Gender, male & $2.31(0.68-7.83)$ & 0.178 & & \\
\hline Liver cirrhosis & $1.69(0.68-4.18)$ & 0.255 & & \\
\hline Platelet, >100 $\left(10^{3} / \mu \mathrm{L}\right)$ & $0.84(0.43-1.22)$ & 0.084 & & \\
\hline Creatinine, $>1.2 \mathrm{mg} / \mathrm{dL}$ & $0.62(0.54-7.11)$ & 0.699 & & \\
\hline Albumin, $<3.5 \mathrm{~g} / \mathrm{dL}$ & - & 0.999 & & \\
\hline Bilirubin, $>1.2 \mathrm{mg} / \mathrm{dL}$ & - & 0.999 & & \\
\hline HCC size $(\mathrm{cm})$ & $1.09(0.97-1.23)$ & 0.151 & & \\
\hline No. of resected segments & $1.72(1.10-2.67)$ & 0.017 & $1.39(0.85-2.28)$ & 0.189 \\
\hline Edema index ${ }^{\mathrm{a}},>0.384$ & $5.20(1.99-13.64)$ & 0.001 & $3.96(1.03-15.17)$ & 0.045 \\
\hline $\mathrm{BMI}\left(\mathrm{kg} / \mathrm{m}^{2}\right)$ & $1.00(0.87-1.14)$ & 0.963 & & \\
\hline Sarcopenia & $1.01(0.25-4.07)$ & 0.993 & & \\
\hline Phase angle, $>5.5$ & $0.36(0.14-0.91)$ & 0.030 & $0.75(0.19-2.96)$ & 0.681 \\
\hline Body cell mass (kg) & $0.94(0.86-1.02)$ & 0.149 & & \\
\hline Fluid infusion during operation (L) & $1.38(1.07-1.79)$ & 0.015 & $1.36(1.04-1.79)$ & 0.026 \\
\hline
\end{tabular}

a, edema index was calculated using extracellular water/total body water. AKI, acute kidney injury; OR, odds ratio; Cl, confidence interval; INR, international normalized ratio; ICGR15 indocyanine green 15' retention test; HCC, hepatocellular carcinoma; BMI, body mass index.

\section{Discussion}

This prospective cohort study revealed that a high preoperative edema index $(>0.384)$ was a significant predictive factor for postoperative ascites or AKI after hepatectomy in patients with HCC. The preoperative edema index was useful, especially for patients with cirrhosis. However, other indicators of BIA such as sarcopenia or phase angle did not predict postoperative complications or short-term survival after hepatectomy.

Previous studies have reported several predictive factors for ascites or AKI after hepatectomy. Advanced age, an increased Model for End-stage Liver Disease score, major hepatectomy, and prolonged surgery were reported as risk factors for AKI after liver surgery (10). Considering postoperative ascites, a study suggested that albumin $<4.0 \mathrm{~g} / \mathrm{dL}$, platelet count $<100 \times 10^{9} / \mathrm{L}$, and operation time $>250 \mathrm{~min}$ increased the incidence of ascites after hepatectomy (29). ICGR15 $>10 \%$, tumor size $>10 \mathrm{~cm}$, and red blood cell transfusion were also identified as risk factors for ascites after hepatectomy (7). In another study, a ChildPugh score of 6 or 7 and major hepatic resection were reported to increase the incidence of post-hepatectomy ascites (30). In summary, the previously reported factors can be grouped into factors that reflect the severity of liver dysfunction and factors that reflect the extent of surgery. These factors have been overcome through careful patient selection, preoperative medical liver disease management, 


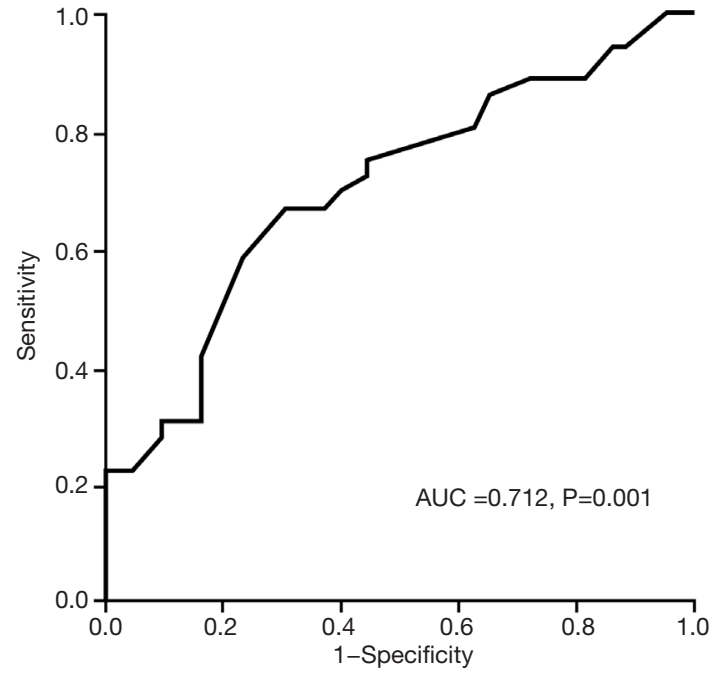

Figure 1 Receiver operating characteristic curve of the edema index for predicting postoperative ascites or acute kidney injury in all patients. and advances in surgical techniques. As seen in the present study, most patients who underwent hepatectomy showed good baseline liver function. Therefore, it is necessary to provide an index that can further evaluate liver function in detail. Recently, liver stiffness measurements via transient elastography have been reported as predictive factors for ascites after hepatectomy (31,32). Liver stiffness measurement is a noninvasive method of evaluating hepatic venous pressure gradient and functional hepatic reserve by estimating hepatic fibrosis (31).

The present study suggests that the edema index obtained by BIA is a simple, easy, and clinically applicable method for volume status assessment of patients with liver disease. A previous study reported an increased edema index in patients with cirrhosis compared to that in healthy controls (25). The edema index also correlated with serum albumin and prothrombin time. Therefore, the edema index can be used to quantify body water redistribution.

Table 3 Risk factors for predicting postoperative ascites or AKI in patients with cirrhosis

\begin{tabular}{|c|c|c|c|c|}
\hline \multirow{2}{*}{ Factors } & \multicolumn{2}{|c|}{ Univariate analysis } & \multicolumn{2}{|c|}{ Multivariate analysis } \\
\hline & OR $(95 \% \mathrm{Cl})$ & $P$ value & OR $(95 \% \mathrm{Cl})$ & $P$ value \\
\hline Age, $\geq 55$ years & $0.83(0.26-2.72)$ & 0.763 & & \\
\hline Hemoglobin (g/dL) & $0.80(0.54-1.18)$ & 0.262 & & \\
\hline Platelet, >100 $\left(10^{3} / \mu \mathrm{L}\right)$ & $0.27(0.05-1.50)$ & 0.134 & & \\
\hline Albumin, $<3.5 \mathrm{~g} / \mathrm{dL}$ & - & 1.000 & & \\
\hline Bilirubin, $>1.2 \mathrm{mg} / \mathrm{dL}$ & - & 1.000 & & \\
\hline INR & $65.16(0.02-200,045.69)$ & 0.308 & & \\
\hline ICGR15, >10\% & $0.48(0.12-1.94)$ & 0.301 & & \\
\hline BMI $\left(\mathrm{kg} / \mathrm{m}^{2}\right)$ & $1.04(0.87-1.23)$ & 0.692 & & \\
\hline Sarcopenia & $1.58(0.24-10.52)$ & 0.637 & & \\
\hline Phase angle, $>5.5$ & $0.48(0.14-1.59)$ & 0.230 & & \\
\hline Body cell mass (kg) & $0.94(0.84-1.04)$ & 0.218 & & \\
\hline Fluid infusion during operation (L) & $1.39(1.00-1.93)$ & 0.048 & $1.38(1.00-1.91)$ & 0.050 \\
\hline Blood loss during operation (L) & $1.17(0.74-1.85)$ & 0.498 & & \\
\hline Transfusion during operation (L) & $1.43(0.87-2.36)$ & 0.157 & & \\
\hline Transfusion after operation (L) & $1.96(0.78-4.96)$ & 0.153 & & \\
\hline
\end{tabular}

a , edema index was calculated using extracellular water/total body water. AKI, acute kidney injury; OR, odds ratio; Cl, confidence interval; INR, international normalized ratio; ICGR15, indocyanine green 15' retention test; HCC, hepatocellular carcinoma; BMI, body mass index. 
Table 4 Risk factors for predicting postoperative ascites or AKI in patients without cirrhosis

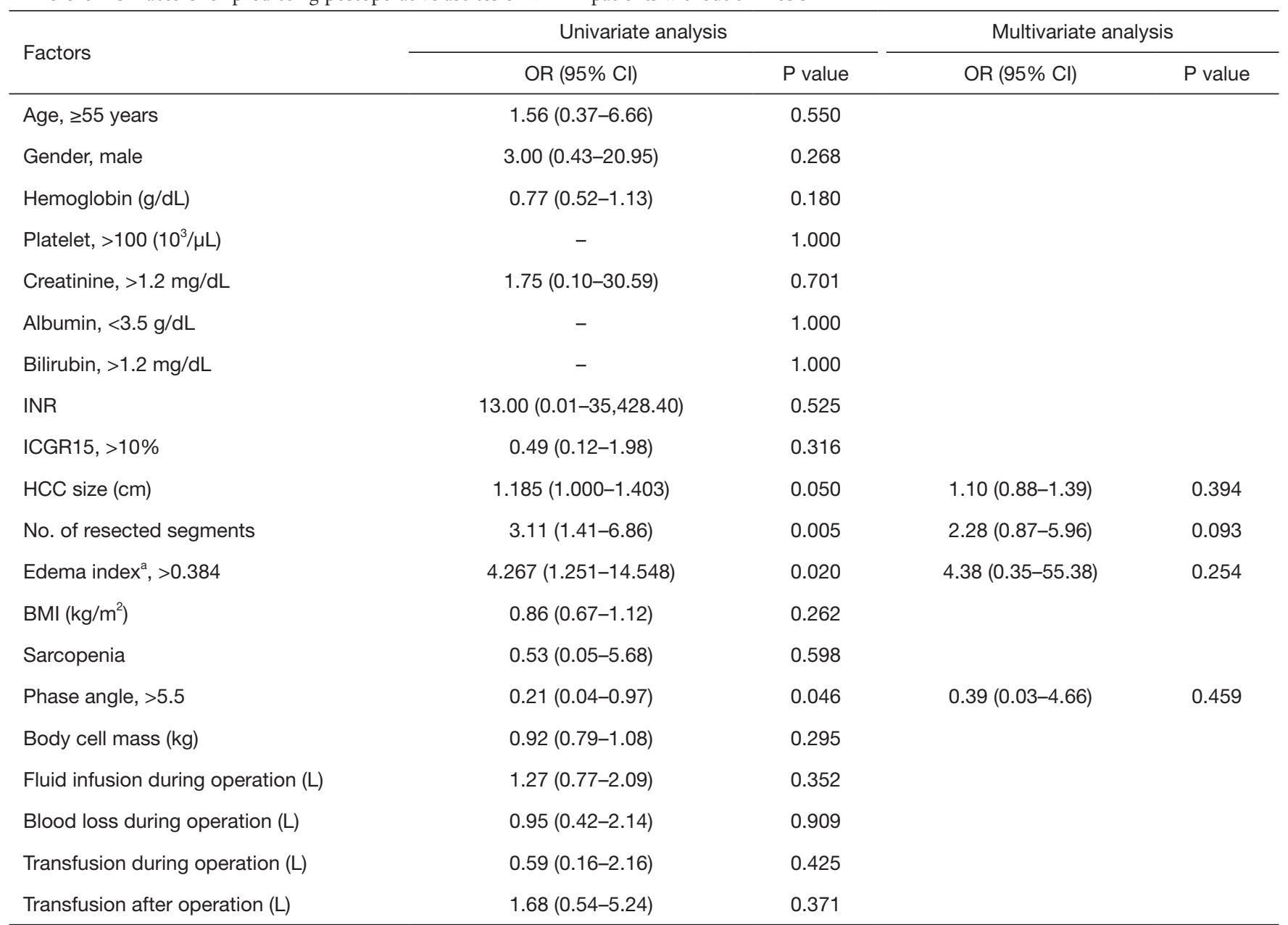

a, edema index was calculated using extracellular water/total body water. AKI, acute kidney injury; OR, odds ratio; Cl, confidence interval; INR, international normalized ratio; ICGR15, indocyanine green 15' retention test; HCC, hepatocellular carcinoma; BMI, body mass index.

According to Hara et al. (25), patients with edema index $\geq 0.398$ demonstrated a higher risk of ascites than those with edema index $<0.398$. Our study demonstrated a difference in the incidence of ascites based on the median value of 0.384. The difference in cutoff value between our study and that of Hara et al. may be because of variations in study population and clinical setting. Their study considered ascites development only in patients with cirrhosis, whereas our study included both patients with and without cirrhosis. Furthermore, the previous study observed that the development of ascites was the natural course in cirrhosis without intervention. However, the current study observed the incidence of ascites after surgical intervention. These differences could have contributed to the lower edema index value for development of ascites in the current study.
BIA has recently become more common because of its convenience and efficacy, and it is widely used in liver disease. Ontanilla-Clavijo et al. reported that a significant correlation was found between peripheral impedance and hemodynamic change, and that impedance can be used for monitoring in patients with cirrhosis of the liver with refractory ascites (33). Studies using sarcopenia as a prognostic indicator in patients with liver cirrhosis (19), and studies predicting mortality as phase angle in patients with cirrhosis (20) and hepatobiliary cancer (21) have also been reported.

Gonzalez et al. reported that since standardization of BIA was lacking, caution was needed in interpreting results from BIA, considering that the prevalence of sarcopenia that has been reported covers a wide range among studies, 
Table 5 Risk factors for predicting postoperative mortality after hepatectomy

\begin{tabular}{|c|c|c|c|c|}
\hline Factors & \multicolumn{2}{|c|}{ Univariate analysis } & \multicolumn{2}{|c|}{ Multivariate analysis } \\
\hline Age, $\geq 55$ years & $0.76(0.11-5.43)$ & 0.787 & $0.96(0.07-13.60)$ & 0.977 \\
\hline Gender, male & $0.04(0.00-1,545.79)$ & 0.539 & - & 0.990 \\
\hline Liver cirrhosis & $0.59(0.08-4.22)$ & 0.597 & & \\
\hline 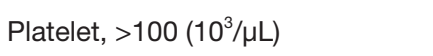 & $24.89(0.00-8,692,674.86)$ & 0.622 & & \\
\hline Creatinine, $>1.2 \mathrm{mg} / \mathrm{dL}$ & $0.05(0.00-91,580,381.97)$ & 0.779 & & \\
\hline Albumin, $<3.5 \mathrm{~g} / \mathrm{dL}$ & $0.05\left(0.00-5.5 \times 10^{16}\right)$ & 0.886 & & \\
\hline Bilirubin, $>1.2 \mathrm{mg} / \mathrm{dL}$ & $0.05(0.00-222,721,769.7)$ & 0.787 & & \\
\hline HCC size (cm) & $1.29(1.08-1.53)$ & 0.005 & $1.72(1.05-2.83)$ & 0.033 \\
\hline No. of resected segments & $2.25(0.93-5.44)$ & 0.073 & & \\
\hline Edema index ${ }^{a},>0.384$ & $0.02(0.00-57.40)$ & 0.328 & & \\
\hline BMI $\left(\mathrm{kg} / \mathrm{m}^{2}\right)$ & $0.82(0.58-1.16)$ & 0.263 & & \\
\hline Sarcopenia & $1.94(0.20-18.87)$ & 0.568 & & \\
\hline Phase angle, $>5.5$ & $3.73(0.39-36.04)$ & 0.255 & & \\
\hline Body cell mass (kg) & $0.99(0.83-1.18)$ & 0.890 & & \\
\hline Fluid infusion during operation (L) & $1.07(0.70-1.64)$ & 0.740 & & \\
\hline
\end{tabular}

a, edema index was calculated using extracellular water/total body water. HR, hazard ratio; Cl, confidence interval; INR, international normalized ratio; ICGR15, indocyanine green 15' retention test; HCC, hepatocellular carcinoma; BMI, body mass index.

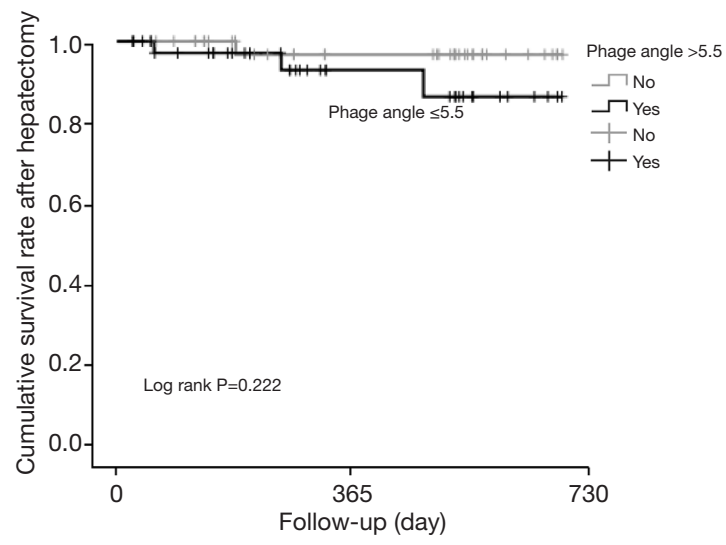

Figure 2 Patients survival rate after hepatectomy according to baseline phage angle. even when conducted in the same population (34). However, BIA is a relatively accurate and convenient test compared to other tests in measuring the presence of sarcopenia (35). In addition, considering that the presence of sarcopenia can be applied as a prognostic factor in patients with liver cirrhosis (19) measuring the presence of sarcopenia using BIA has great clinical relevance.

However, in the present study, sarcopenia or phase angle was not significantly predictive of morbidity or mortality after hepatectomy. Considering the relatively short followup duration of our study (median 10.7 months), the role of BIA was not evident in predicting short-term survival after hepatectomy. The only significant factor for predicting short-term mortality was tumor burden. In fact, all four 
patients who died demonstrated HCC progression. Further studies showing whether sarcopenia or phase angle can predict long-term mortality are needed.

This study has a few limitations. Although the study was conducted on patients with early-stage operable HCC, we did not control for HCC stage in the study. Likewise, although the study included only patients with preserved liver function who underwent surgery, the study population had various etiologies. These factors could also have affected postoperative morbidity.

There is also a limitation that our study could not consider all other factors that could affect the edema index. Nevertheless, we thought the edema index may reflect underlying liver decompensation that may not be clearly identified with conventional tests.

In conclusion, the preoperative edema index can be used to predict the incidence of ascites or AKI after hepatectomy, particularly in patients with liver cirrhosis. BIA could provide additional clinical information regarding postoperative complications in patients with HCC scheduled for surgery.

\section{Acknowledgments}

Funding: This research was supported by the Bio \& Medical Technology Development Program of the National Research Foundation (NRF) funded by the Korean government (MSIT) (NRF-2018M3A9E8023861, 2019R1C1C1004580).

\section{Footnote}

Reporting Checklist: The authors have completed the TRIPOD reporting checklist. Available at http://dx.doi. org/10.21037/atm-20-5194

Data Sharing Statement: Available at http://dx.doi. org/10.21037/atm-20-5194

Peer Review File: Available at http://dx.doi.org/10.21037/ atm-20-5194

Conflicts of Interest: All authors have completed the ICMJE uniform disclosure form (available at http://dx.doi. org/10.21037/atm-20-5194). The authors have no conflicts of interest to declare.

Ethical Statement: The authors are accountable for all aspects of the work in ensuring that questions related to the accuracy or integrity of any part of the work are appropriately investigated and resolved. The study was conducted in accordance with the Declaration of Helsinki (as revised in 2013). The study was approved by the Institutional Review Board of Ajou University hospital (AJIRB-MED-OBS-16-287), and all patients provided informed consent.

Open Access Statement: This is an Open Access article distributed in accordance with the Creative Commons Attribution-NonCommercial-NoDerivs 4.0 International License (CC BY-NC-ND 4.0), which permits the noncommercial replication and distribution of the article with the strict proviso that no changes or edits are made and the original work is properly cited (including links to both the formal publication through the relevant DOI and the license). See: https://creativecommons.org/licenses/by-nc-nd/4.0/.

\section{References}

1. Bray F, Ferlay J, Soerjomataram I, et al. Global cancer statistics 2018: GLOBOCAN estimates of incidence and mortality worldwide for 36 cancers in 185 countries. CA Cancer J Clin 2018;68:394-424.

2. Fan ST, Lo CM, Liu CL, et al. Hepatectomy for hepatocellular carcinoma: toward zero hospital deaths. Ann Surg 1999;229:322-30.

3. Torzilli G, Makuuchi M, Inoue K, et al. No-mortality liver resection for hepatocellular carcinoma in cirrhotic and noncirrhotic patients: is there a way? A prospective analysis of our approach. Arch Surg 1999;134:984-92.

4. Wei AC, Tung-Ping Poon R, Fan ST, et al. Risk factors for perioperative morbidity and mortality after extended hepatectomy for hepatocellular carcinoma. Br J Surg 2003;90:33-41.

5. Kusano T, Sasaki A, Kai S, et al. Predictors and prognostic significance of operative complications in patients with hepatocellular carcinoma who underwent hepatic resection. Eur J Surg Oncol 2009;35:1179-85.

6. Ishizawa T, Hasegawa K, Kokudo N, et al. Risk factors and management of ascites after liver resection to treat hepatocellular carcinoma. Arch Surg 2009;144:46-51.

7. Chan KM, Lee CF, Wu TJ, et al. Adverse outcomes in patients with postoperative ascites after liver resection for hepatocellular carcinoma. World J Surg 2012;36:392-400.

8. van Mierlo KMC, Schaap FG, Dejong CHC, et al. Liver resection for cancer: New developments in prediction, 
prevention and management of postresectional liver failure. J Hepatol 2016;65:1217-31.

9. Chen LP, Li C, Wang C, et al. Risk factors of ascites after hepatectomy for patients with hepatocellular carcinoma and hepatitis B virus-associated cirrhosis. Hepatogastroenterology 2012;59:292-5.

10. Lim C, Audureau E, Salloum C, et al. Acute kidney injury following hepatectomy for hepatocellular carcinoma: incidence, risk factors and prognostic value. HPB (Oxford) 2016;18:540-8.

11. Slankamenac K, Breitenstein S, Held U, et al.

Development and validation of a prediction score for postoperative acute renal failure following liver resection. Ann Surg 2009;250:720-8.

12. Tomozawa A, Ishikawa S, Shiota N, et al. Perioperative risk factors for acute kidney injury after liver resection surgery: an historical cohort study. Can J Anaesth 2015;62:753-61.

13. Bredt LC, Peres LAB. Risk factors for acute kidney injury after partial hepatectomy. World J Hepatol 2017;9:815-22.

14. Zillikens MC, van den Berg JW, Wilson JH, et al. Wholebody and segmental bioelectrical-impedance analysis in patients with cirrhosis of the liver: changes after treatment of ascites. Am J Clin Nutr 1992;55:621-5.

15. Fosbøl MØ, Zerahn B. Contemporary methods of body composition measurement. Clin Physiol Funct Imaging 2015;35:81-97.

16. Toso S, Piccoli A, Gusella M, et al. Altered tissue electric properties in lung cancer patients as detected by bioelectric impedance vector analysis. Nutrition 2000;16:120-4.

17. Gupta D, Lis CG, Dahlk SL, et al. Bioelectrical impedance phase angle as a prognostic indicator in advanced pancreatic cancer. Br J Nutr 2004;92:957-62.

18. Gupta D, Lammersfeld CA, Burrows JL, et al. Bioelectrical impedance phase angle in clinical practice: implications for prognosis in advanced colorectal cancer. Am J Clin Nutr 2004;80:1634-8.

19. Kim G, Kang SH, Kim MY, et al. Prognostic value of sarcopenia in patients with liver cirrhosis: a systematic review and meta-analysis. PLoS One 2017;12:e0186990.

20. Belarmino G, Gonzalez MC, Torrinhas RS, et al. Phase angle obtained by bioelectrical impedance analysis independently predicts mortality in patients with cirrhosis. World J Hepatol 2017;9:401-8.

21. Yasui-Yamada S, Oiwa Y, Saito Y, et al. Impact of phase angle on postoperative prognosis in patients with gastrointestinal and hepatobiliary-pancreatic cancer. Nutrition 2020;79-80:110891.
22. Barao K, Abe Vicente Cavagnari M, Silva Fucuta P, et al. Association Between Nutrition Status and Survival in Elderly Patients With Colorectal Cancer. Nutr Clin Pract 2017;32:658-63.

23. Axelsson L, Silander E, Bosaeus I, et al. Bioelectrical phase angle at diagnosis as a prognostic factor for survival in advanced head and neck cancer. Eur Arch Otorhinolaryngol 2018;275:2379-86.

24. Schütte K, Tippelt B, Schulz C, et al. Malnutrition is a prognostic factor in patients with hepatocellular carcinoma (HCC). Clin Nutr 2015;34:1122-7.

25. Hara N, Iwasa M, Iwata K, et al. Value of the extracellular water ratio for assessment of cirrhotic patients with and without ascites. Hepatol Res 2009;39:1072-9.

26. Chen LK, Liu LK, Woo J, et al. Sarcopenia in Asia: consensus report of the Asian Working Group for Sarcopenia. J Am Med Dir Assoc 2014;15:95-101.

27. Kellum JA, Lameire N, KDIGO AKI Guideline Work Group. Diagnosis, evaluation, and management of acute kidney injury: a KDIGO summary (Part 1). Crit Care 2013;17:204.

28. Hsieh FY, Bloch DA, Larsen MD. A simple method of sample size calculation for linear and logistic regression. Stat Med 1998;17:1623-34.

29. Yoshikawa T, Nomi T, Hokuto D, et al. Risk factors for postoperative ascites in patients undergoing liver resection for hepatocellular carcinoma. World J Surg 2017;41:2095-100.

30. Choi SW, Shin WY, Lee KY, et al. Risk factors of postoperative ascites on hepatic resection for hepatocellular carcinoma. Ann Hepatobiliary Pancreat Surg 2016;20:153-8.

31. Rajakannu M, Cherqui D, Ciacio O, et al. Liver stiffness measurement by transient elastography predicts late posthepatectomy outcomes in patients undergoing resection for hepatocellular carcinoma. Surgery 2017;162:766-74.

32. Li C, Zhang JY, Zhang XY, et al. FibroScan predicts ascites after liver resection for hepatitis B virus-related hepatocellular carcinoma: a prospective cohort study. Int J Surg 2015;20:21-5.

33. Ontanilla-Clavijo G, Ampuero J, Borreguero S, et al. Usefulness of bioelectrical impedance analysis for monitoring patients with refractory ascites. Rev Esp Enferm Dig 2019;111:223-7.

34. Gonzalez MC, Barbosa-Silva TG, Heymsfield SB. Bioelectrical impedance analysis in the assessment 
Page 12 of 12

of sarcopenia. Curr Opin Clin Nutr Metab Care 2018;21:366-74.

35. Aleixo GFP, Shachar SS, Nyrop KA, et al. Bioelectrical
Lee et al. BIA for predicting postop complication in HCC

Impedance Analysis for the Assessment of Sarcopenia in Patients with Cancer: A Systematic Review. Oncologist 2020;25:170-82.

Cite this article as: Lee GH, Cho HJ, Lee G, Kim HG, Wang HJ, Kim BW, Lee MY, Yoon SY, Noh CK, Seo CW, Eun JW, Cheong JY, Cho SW, Kim SS. Bioelectrical impedance analysis for predicting postoperative complications and survival after liver resection for hepatocellular carcinoma. Ann Transl Med 2021;9(3):190. doi: 10.21037/atm-20-5194 